\title{
Analyzing Smart Devices that Support Elderly Care: Focusing on Multidisciplinary Approach
}

\author{
Sunhyung Lee1), Sungjun Park2), Joonhee Ahn3), Doonam Oh${ }^{4}$ ), Seunghae Lee5)
}

\begin{abstract}
This study examined smart devices that can support elderly care, exploring their advantages, such as instant access to relevant information and efficient interactions between the elderly and caregivers. To achieve the goal, this study conducted a case study for such devices, focusing on their usages for elderly care. The case analysis is based on the multidisciplinary model by Dara-Abrams and organized Gerontechnology, especially smart devices into five different domains depending on the elderly care support types. The five elderly care support domains include comprehensive, environmental, social, cognitive, and physical supports. In order to choose smart devices supporting elderly care, five researchers having experience in multi-year convergence studies were chosen in each academic field. They select devices based on the selection criteria, assuming that each researcher represents each field. Afterwards, this study analyzed the content based on the selected devices to determine which domains were included to support the elderly care. The results show that smart devices provide one or two support features rather than comprehensive support for elderly care. Older adults experience various support needs such as cognitive, mental, social supports as well as physical support as they age. Thus, this study suggests that smart device development should incorporate diverse support needs for comprehensive and effective support provisions.
\end{abstract}

Keywords: Caregiving for Elderly, Gerontechnology, Smart Devices, Multidisciplinary Model

Received(February 28, 2020), Review Result(1st: April 01, 2020, 2nd: May 22, 2020), Accepted(May 27, 2020)

1) (Associate Professor, Corresponding Author) 31066 Dept. of Social Welfare, Hoseo Univ., 12 Hoseodae-gil, Dongnam-gu, Cheonan-si, Chungcheongnam-do, Republic of Korea

email: yisunh@hoseo.edu

2) (Technology Director of ForenDream Co.) 04529 ForenDream Co., 10th Floor, 7 Namdaemun-ro, Jung-gu, Seoul, Republic of Korea

email: sjpark.jesus@gmail.com

3) (Associate Professor) 31066 Dept. of Social Welfare, Hoseo Univ., 12 Hoseodae-gil, Dongnam-gu, Cheonan-si, Chungcheongnam-do, Republic of Korea

email: ja390@hoseo.edu

4) (Associate Professor) 31499 Dept. of Nursing, Hoseo Univ., 79-20 Hoseo-ro, Baebang-eup,Asan-si, Chungcheongnam-do, Republic of Korea

email: doonoh@hoseo.edu

5) (Professor) 02138550 Huntington Ave. Interior Design Dept., Wentworth Institute of Technology, Boston, MA

email: lees24@wit.edu 


\section{Introduction}

Extended life expectancy has led to a rapid increase in the number of super-aged people who require care in South Korea. As of 2019, the proportion of people aged $\geq 65$ is $14.9 \%$ or $7,685,000$, and the number of the super-aged people aged $\geq 80$ amounts to $1,857,000$, which corresponds to $28.3 \%$ of the elderly aged $\geq 65$ (NSO, 2019)[1]. The proportion of super-aged people, which only comprised $0.8 \%$ of the entire population $(365,000)$ in 1995 , increased by 5.08 -fold in 20 years, and the increase is expected to be 10.37 -fold increase $(3,875,000,7.17 \%)$ in the next 20 years (by 2035)(NSO, 2019)[1]. Overall, the number of elderly people aged $\geq 80$ is increasing significantly. Individuals age gradually, and demands care thus increases - as the status of their health deteriorates. Initially, family members such as a spouses or children take care of the elderly, but- as care needs arise, people begin to engage with public care systems that offer professional care, called Long-term Care for Senior Citizens. This transition requires close interactions between public and private care providers for successful care. People experience different challenges in the private and public care systems[2].

Developed countries have been seeking solutions that support elderly care in smart devices to alleviate the caregivers' physical and mental burden[3]. Some studies have shown that the use of devices such as computers and multimedia, which are not smart devices, still has a sociopsychological effect. A study by Irvine et al. reported that the use of computers by the elderly living in facilities had effects in improving self-control, reducing depression or aggressiveness[4]. Smart technology has several advantages for elderly care, including prompt provision of useful information, and facilitation of close interactions between the elderly and caregivers or between caregivers. To explore the advantages and uses of smart technology, this study conducted a case study of smart technology devices used overseas that support elderly care. These devices can be utilized to alleviate burdens assumed by elderly caregivers, in both public and private settings. Smart devices may empower the elderly so that they can live more comfortably and independently and assist them in maintaining and improving their psychological and physical wellbeing. This study also analyzed apps and websites that utilize smart devices and are available in the field of elderly care. It adopted an existing framework to examine the uses and benefits of smart devices in a systemic manner. The results of this case study will help developers identify optimal directions for smart device development and serve as their basis for measures to resolve elderly care issues in South Korea. 


\section{Literature Review}

\subsection{Characteristics of Elderly Caregiving}

Elderly care is typically perceived as physical care. However, it also includes economic, psychological, and emotional care. As people grow older, their physical health deteriorates and they develop attendant mental and emotional care needs. Elderly care can be divided into several types, including the care that is to be provided continuously, and the care that is offered on a daily, weekly, monthly, or yearly basis based on the frequency and category of a task. The types of cares can be trivial or complex and they vary in intensity and frequency (See [Fig. 1])[5]. Caregiving is not only multidimensional in content, but can be approached from different directions based on the subject and form of care.

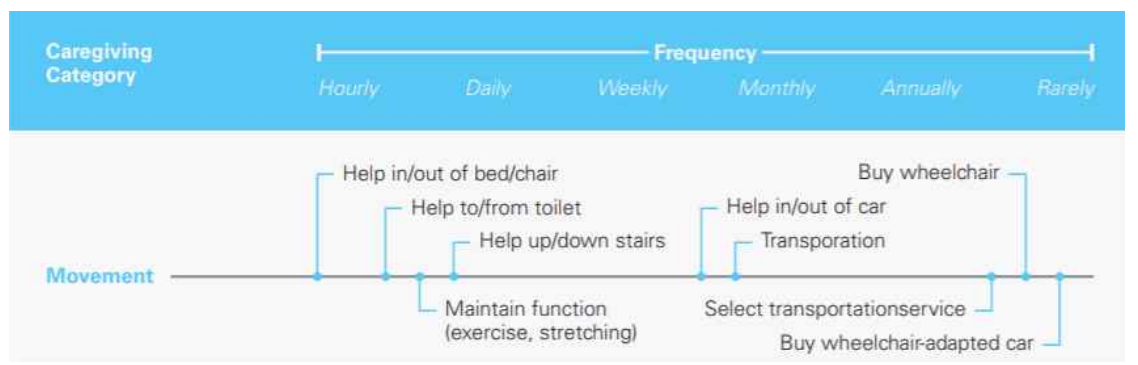

[Fig. 1] Example of a Task Matrix, Showing the Wide Range of Frequencies of Caregiving Tasks. [source] NAC(2014).

According to a Pew Survey in the United States, 39\% of adults are family care providers, and $70 \%$ of family caregivers work outside the home, which prevents family caregivers from being primary caregivers for the elderly[2]. South Koreans are also experiencing changes in traditional family structures for various reasons including family nuclearization, an increase in single-person households, and an increasing never-married rate. Furthermore, as individualcentered values replace communal family values, a sense of responsibility for one's families is also weakening.

However, the Korean elderly remain hightly dependent on their family members. Based on their responses, $59.4 \%$ of the elderly Koreans received help from their cohabitating children (care take-up rate), while only $22.7 \%$ provided help for their cohabitatingon children (care provision rate). Thus, the care take-up rate of among the elderly compared to their children. A comparison with cohabiting and non-cohabiting children showed that the care take-up rate by 
non-cohabiting children is much lower as $43 \%$. In contrast, the number of elderly who received care remained high. Meanwhile, a study of social network types among in-facility seniors showed that social networks were divided into the following three types; child-dependent $(68.3 \%)$, isolated $(13.9 \%)$, and limitedly multi-connected $(17.8 \%)[6]$. While the physical burden of a family on elderly care decreases, while the psychological burden remains.

\subsection{Challenges of the Caregivers Experience}

Family members face challenging situations in providing care for the elderly in their families . Traditionally in South Korea, daughters-in-law who stay home have taken care of their parents-in-law. This is rarely possible now because children's families seldom live with their parents, and an increasing number of women (daughters-in-law or daughters) work outside the home. These structural changes in the family system, along with a shift in values toward and perceptions of elderly care have made continuing family care for the elderly more challenging. The elderly care policies in South Korea, such as the Long-term Care Insurance for Senior Citizens, are based on the long-term care classification level. This adds another layer of difficulty for families seeking Long-term Care Insurance benefits. Because the process to receiving Long-term Care Insurance is complex and challenging, they need to obtain certain classification levels before they can apply for Long-term Care Insurance

Another difficulty that family members face during this process is finding appropriate care facilities and professional caregivers. Despite the growing number of nursing facilities, including nursing homes and hospitals, families often struggle to find appropriate facilities. Many facilities fail to meet the various demands of the elderly and their families, and so they consider them insufficient. Another challenge is the quality of the caregiving workforce, including long-term care facility staff and caregivers. Families experience a difficult time acquiring relevant information regarding benefits for the elderly and find it hard to rely on services from caregivers. For these reasons, families perceive long-term care services as insufficient and encounter a large gap between the supply and demand of quality caregivers[7]

Developed countries have begun utilizing smart technologies to actively responding to various issues that can occur in the field of elderly care. In particular, these countries have started to focus on supporting the independent living of the elderly, regardless of their individual situations or environments. The United States implemented the Family Caregiver Support Program by revising the Older Act in 2000, prescribing the obligations of local governments to provide various services for families and unofficial caregivers. The U.S. has 
thus attempted to utilize smart technology-based integrated systems to improve the quality of life of the elderly and long-term care workers by raising the efficiency Meanwhile, the European Union(EU) has conducted a joint research and development project called Ambient Assisted Living (AAL). It have performed various studies on user-centered smart devices and environments that support elderly care. To address the ongoing paradigm shift of the Fourth Industrial Revolution and Korea's super-aging society, smart technology use will be critical, and there have been studies that explored theses needs[8-10].

\subsection{The Positive Impact of Smart Devices in the Elderly Care Field}

In particular, the application of smart technology to the care domain has the following advantages. First, such technology can help address the needs of the elderly and caregivers. The precarious nature of elderly people's health means that they can experience emergency that supports urgent responses, such as a fall or a wandering. The latest technologies can quickly identify the risks the elderly face, and immediately contact agencies or personnel who can respond to the situations. Furthermore, they enable caregivers to give instantaneous information about the symptoms and circumstances. This can help caregivers enable to respond quickly to elderly at-risk

Second, smart devices allow two-way communications with society, which can enhance the interactions between the elderly and caregivers, and between caregivers. Hearing and vision loss, which most elderly individuals experience to some extent, make communication difficult. In particular, as because aging changes the structure of the brain, the elderly struggle with multitasking and the selection of appropriate vocabulary, and they often become talkative and unfocused in conversation. An increase in the elderly's communication with society is advantageous in that such increased communication can delay cognitive decline or probable communication problems in the future[11]. Thus, enabling elderly individuals to engage in more social interaction and thereby enhancing their social connectivity could directly or indirectly reduce the support burdens of placed on a families. To achieve this, developed countries are seeking to establish supports system that provides immediate information and facilitates interactive communication[3][12].

Third, some studies have shown that the use of devices has a sociopsychological effects. For example, one study asked elderly people with dementia or mild cognitive impairment (MCI) to write their autobiographies and periodically review the writing using a multimedia device with their families. By analysis of the interview and video data, devices aided family members in 
remembering and better understanding their loved ones, and stimulated social interactions with family members and with formal caregivers[13].

\section{Research Methods}

\subsection{Multidisciplinary Approach Model}

Dara-Abrams[14] used a multidisciplinary model to describe the aging process and changes over time and this model provides useful theoretical approach for describing devices for the elderly. The same study proposed an integrated model that describes humans as multi-layered rather than single-layered, and that frames human behavior consists as consisting of both the physical interior and the interactive exterior. More specifically, the first layer refers to the physiological functions of the human body and the second layer refers to the physical activities of the human body, the related physical skills, activities and movements. And the third layer refers to cognitive activities, and the fourth layer refers to the various interactive activities in which individuals participate in society. The same study pointed out that the previous studies of gerontechnology have been focused mainly on the physiological and physical approaches.

Given the relative scarcity of related studies, this study was conducted based on Dara-Abrams's study and in reference to several other studies. As a result, it examined devices for elderly care support devices from an integrated support perspective the physical aspects of the human body, environmental support, cognitive support, and social support. (See [Fig. 2]).

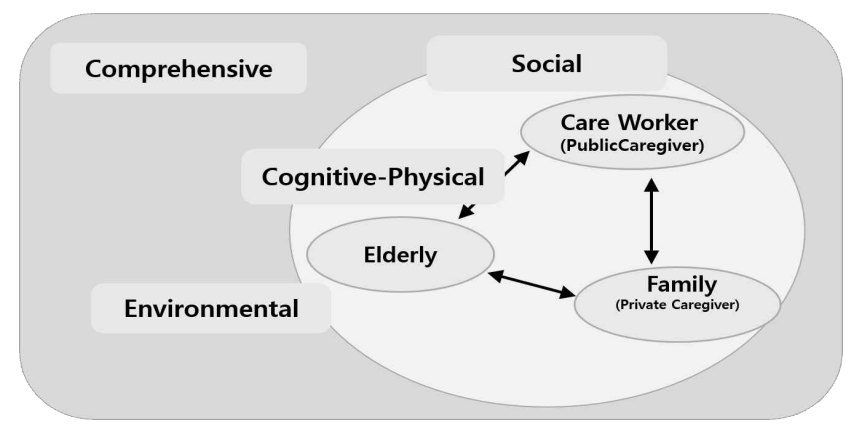

[Fig. 2] Theoretical Framework of Method Used by Smart Devices for Caregiving for the Elderly

\subsection{Smart Devices Classification for Analysis}

Based on this analytical framework, this study divided elderly care devices into five domains based on their functions using this classification, the two most representative devices among 
the devices expected to provide care support functions in each domain were selected. To select devices, five researchers were chosen in relevant academic field: two elderly welfare professors with having experience in multi-year convergence studies, one engineering professor with developing games for the elderly, one elderly nursing professor, and one senior facility design professor. With each researcher serving as a representative of his or her respective field, th five researchers conducted a total of five online and offline meetings. Researchers select devices based on the following selection criteria : Comprehensive support included 3 or more different domains-common : Smart technology application- Elderly care support function includedRecently developed-Commercial/prototype type. Afterwards, this study analyzed the content using the selected devices to determine which elderly care support domain they addressed.

[Table 1] Application Classifications, Smart Device, Elderly Care Support Services, and Selected Cases by Domain

\begin{tabular}{|c|c|c|c|c|}
\hline \multicolumn{3}{|l|}{ Category } & \multirow{2}{*}{ Service detail } & \multirow{2}{*}{$\begin{array}{l}\text { Selected elderly } \\
\text { care devices }\end{array}$} \\
\hline \multicolumn{2}{|c|}{ Support aspects } & Purpose & & \\
\hline \multicolumn{2}{|c|}{ - Comprehensive support } & $\begin{array}{l}\text {-Comprehensiv } \\
\text { e support }\end{array}$ & $\begin{array}{l}\text { Comprehensive } \\
\text { encompassing physical environment, } \\
\text { social interaction, cognitive and } \\
\text { physical support }\end{array}$ & $\begin{array}{l}\text { Gra nd } \mathrm{C} \text { are, } \\
\text { IN2L® }\end{array}$ \\
\hline \multirow[b]{2}{*}{$\begin{array}{l}\text {-Environm } \\
\text { ental } \\
\text { support }\end{array}$} & $\begin{array}{l}\text { - Care } \\
\text { management } \\
\text { - Schedule }\end{array}$ & \multirow[b]{2}{*}{$\begin{array}{l}\text { - Prevention } \\
\text { - Independent } \\
\text { living }\end{array}$} & $\begin{array}{l}\text { - Personal schedule management } \\
\text { - Notification of time to take } \\
\text { medicine and time to exercise }\end{array}$ & CareZone \\
\hline & $\begin{array}{l}\text { - Information } \\
\text { provision }\end{array}$ & & $\begin{array}{l}\text { - Elderly rehabilitation / emergency } \\
\text { hospital / elderly welfare facility } \\
\text { information } \\
\text { - Medical and nursing stuff } \\
\text { information } \\
\text { - Health / care provider information }\end{array}$ & $\begin{array}{l}\text { C a r i n g } \\
\text { Connections }\end{array}$ \\
\hline $\begin{array}{l}\text { S o c i a } 1 \\
\text { support }\end{array}$ & $\begin{array}{l}\text { - Communication } \\
\text { - Governance }\end{array}$ & $\begin{array}{l}\text { - Social } \\
\text { interaction } \\
\text { - Social } \\
\text { network } \\
\text { formation }\end{array}$ & $\begin{array}{l}\text { - Elderly-family interaction } \\
\text { : Video call/ photo sharing/ online } \\
\text { chat, etc. } \\
\text { - Long-term care personnel-family } \\
\text { interaction: communication } \\
\text { - Fostering community with other } \\
\text { friends, relatives and neighbors }\end{array}$ & Nectar, YOOM \\
\hline $\begin{array}{l}\text { Cognitive } \\
\text { support }\end{array}$ & $\begin{array}{l}\text { - Serious game } \\
\text { - Leisure use }\end{array}$ & $\begin{array}{l}\text { - Reward } \\
\text { - Joy } \\
\text { - Improved } \\
\text { cognition }\end{array}$ & $\begin{array}{l}\text { Game for improving cognitive } \\
\text { awareness to prevent dementia } \\
\text { Exercise/leisure using multimedia }\end{array}$ & $\begin{array}{ll}\text { Kichen } & \text { Game, } \\
\text { vTime } & \text { (Social } \\
\text { VR) } & \end{array}$ \\
\hline $\begin{array}{l}\text { Physical } \\
\text { support }\end{array}$ & $\begin{array}{l}\text { - Health status } \\
\text { measurement and } \\
\text { detection }\end{array}$ & $\begin{array}{l}\text { - Health } \\
\text { status check } \\
\text { - Safety }\end{array}$ & $\begin{array}{l}\text { - Detection of emergency call } \\
\text { function / activity } \\
\text { - Detection of various health }\end{array}$ & $\begin{array}{l}\text { CarePredict }{ }^{\circledR}, \\
\text { ROSETTA }\end{array}$ \\
\hline
\end{tabular}




\begin{tabular}{|c|c|c|}
\hline & $\begin{array}{l}\text { - Health } \\
\text { information } \\
\text { provision } \\
\text { through system }\end{array}$ & $\begin{array}{l}\text { condition } \\
\quad \text { (Diabetes/blood pressure/various } \\
\text { major symptoms, vital signs) } \\
\text { - Periodic delivery of elderly status } \\
\text { information to families(Automated } \\
\text { system) }\end{array}$ \\
\hline
\end{tabular}

- Comprehensive Support Domain (Grandcare, IN2L) - The integrated support systems for comprehensive care support provides services by integrating multiple devices and functions into single systems with various purposes and functions. Typical examples of integrated support systems include Grandcare system[15], IN2L[16], and Telikin[17]. The Grandcare system is currently commercially available in the United States (see [Fig. 3]). This system's functions include medical services, including detection of elderly individual's activities (detection and notification of fall and low-level activity), telemedicine, and medication management, in addition to communication and information exchanges with family, friends and relatives. This system also includes communication with caregivers, and medical providers, such as sending messages, photos, and videos. This system has the advantage of being accessible from various types of devices such as computers, tablets, and wireless phones.

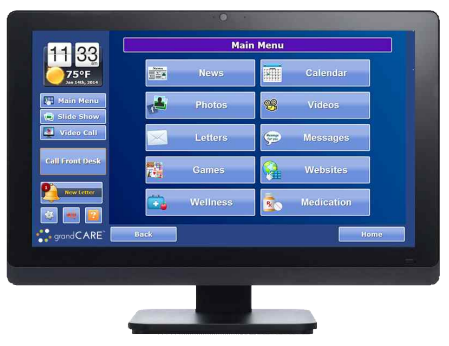

[Fig. 3] GrandCARE System
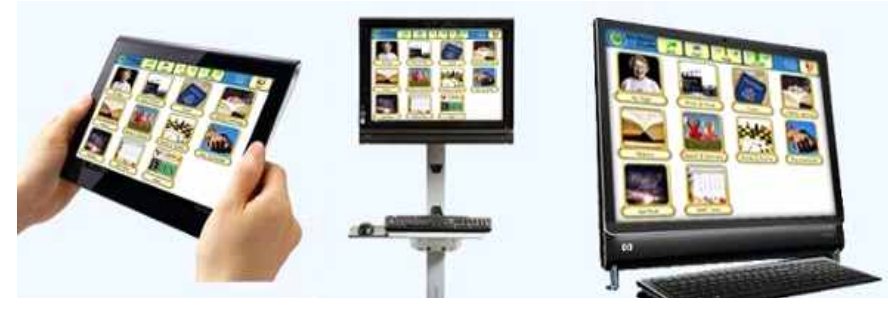

[Fig. 4] IN2L Interface (Left) and Use Case (Right)

On the other hand, the Telikin and IN2L are simpler integrated systems that focus more on social accessibility (see [Fig. 4]). Both systems allow users to access a variety of information through a web browsers from a single device (including a computers). They enable leisure time such as e-mail, video calls, photo sharing, and various games with family and friends. IN2L provides a touch screen for ease of use, enabling relatively easy access with multiple interfaces. Furthermore, this system contains 1,000 or more different types of content and can be customized to individual's interests and circumstances.

- Environmental Support Domain (CareZone App) - Environmental support for the elderly 
is provided by constructing external physical environments for elderly care, which can that contain systems both for managing elderly care and for providing related information. First, elderly care management systems have been developed to provide information, measure access to resources, facilitate in-family coordination/communication, provide daily care for the elderly and to increase the accessibility of these services through wearable technology. The CareZone app for the elderly, children, and the disabled, which serves as a health records tool, is a representative example[18].

The following section focus on the information provision systems. Most information provision for the elderly involves health-related information, and systems for providing that information often target both the elderly and the non-elderly. Elderly care typically takes the form of transitioning from a private setting(e.g. family) to a public setting. This process often requires information regarding the provision of elderly care, as well as information regarding public institutions/workforces, services, and costs. The various information required during the process of transitioning from private to public settings, includes information regarding the caring services that can be provided by the Long-term Care Insurance for Senior Citizens are related expenses as well as information about job openings/applications of caregivers.

- Social Support Domain (Nectar Launcher, YOOM) - Interactive communication and information exchange between caregivers and beneficiaries would enable care to be more immediate and systematic. Nectar Launcher is a representative communication facilitation system[18] (See [Fig. 5]). Although Nectar Launcher is not an exclusively designed for the elderly, simple design enables the elderly and children to easily use it on their smartphone. Its enlarged fonts make it easier to read and write, and the large buttons easy to press. The app enables users to quickly get in touch with their families, and includes functions to track of their paths, or contact someone close to the user's smartphone by shaking the hand three times in case of an emergency. These features make communication with family members swift and accessible.

Meanwhile, since 2008, the European Union has been working on large projects to both develop new smart devices for the elderly and improve the usability of smartphones and other devices already in use through the concept of Ambient Assisted Living (AAL)[3][19][20]. Japan is the single Asian country that is involved in the AAL project, exerting its efforts to resolve social isolation issue of the elderly through smart technologies. As part of these efforts, the EU has developed a new interface, YOOM, to enhance the social connectedness of the elderly, this system utilizes the "TelePresence Tablet", which enables users to develop natural bonds by 
participating in activities together using the touchpad (See [Fig. 6]).
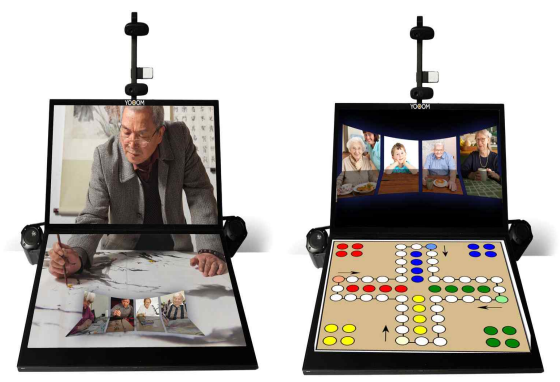

[Fig. 5] Nectar Launcher App Screen
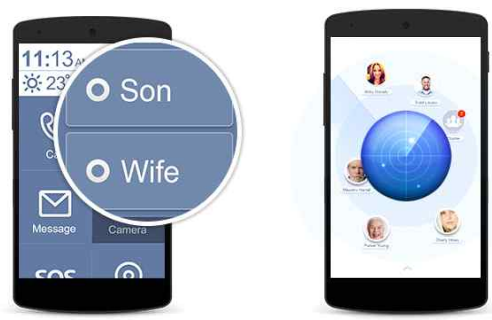

[Fig. 6] TelePresence Tablet: YOOM Use Case

- Cognitive Support Domain(Kichen Game, vTime) - One area of focus in device development is improving the cognitive functions of elderly individuals. This includes using virtual reality (VR) technology develop leisure content for the elderly by using virtual reality (VR) technology. For example, in the VERVE Project, European researchers are collaborating to develop games and VR-based content to improve comprehensive functions, including health, relationship recovery, leisure, and the cognitive functions of the elderly. Within the VERVE Project, the Memory Motivation Virtual Experience(MeMoVE) utilizes virtual game-based functional game content to improve various functions of the elderly. The figures below shows the MeMoVE VR system's functional game content[20] (See [Fig. 7]). Meanwhile, the vTime VR system is a VR system based on a network environment that emphasizes the social relationships among users. It enables current or new friends can gather together in vast scenic places or unvisited places to revitalize social communities through chatting(See [Fig. 7]).

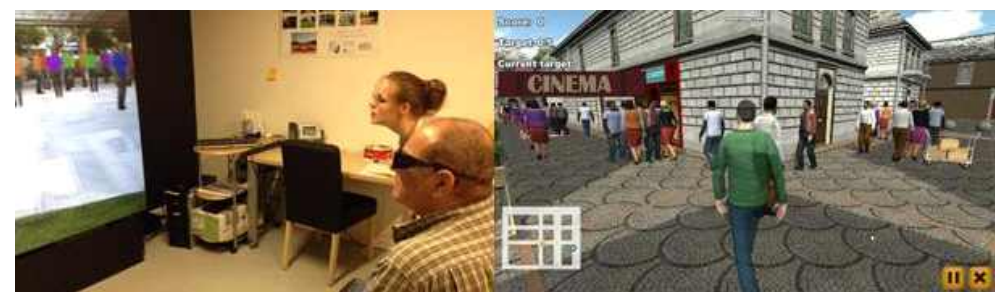

(a) Functional game "Kichen Game" to alleviate depression and promote motivation, (b) Functional game "City Quest" to promote social connection and prevent Parkinson's disease for the elderly

[Fig. 7] VR-based Functional Game Content

- Physical Care Support Domain(CarePredict, ROSETTA) - The most common domain using IT or ST technology in the elderly welfare area is the health problem support domain. CarePredict is a system that monitors the daily life patterns of the elderly, providing 
information regarding daily life patterns for families who do not live together and notifying them of abnormalities through the constant and repetitive reporting[21]. CarePredict can reduce the psychological burden of family members who worry about their elderly relatives because they live separately and can also help people cope with lonely death and emergencies. In addition, systems such as ROSETTA and MYLIFE developed in the European AAL project, are have reportedly enjoyed relatively success[22]. MYLIFE reminds people suffering memory problems or dementia to check the time, keep important appointments, and maintain the social connections that they can control[23].

\section{Case Analysis Results}

This study's analysis of various devices that can support elderly care functions produced the following results (See [Table 2]). [Case 1] GrandCare in the integrated support domain supports the functions in all five domains proposed in this study, and [Case 2] iN2L has contents in of four domains. Within this domain, [Case 2] is missing care management and physical health monitoring content. The other cases have content in one or two domains. The detailed results are as follows. [Case 3] CareZone has content in both care management and care-related information provision; and [Case 4] Caring Connection has information provision in the physical domain, as well as some content in the social communication domain. Nectar, which corresponds to [Case 5] in the social interaction support domain, only included content for promoting social communication, and [Case 6] YOOM has content for promoting social communication and cognitive functional games. In the cognitive support domain, [Case 7] Kichen Game and [Case 8] vTimehave have functional game contents for cognitive improvement; as well as social interaction improvement content due to the characteristics of Social VR. Finally, in the physical support domain, [Case 9] CarePredict and ROSETTA, both only contain health status monitoring.

Next, the results of the content-based analysis were as follows. Two devices contain the comprehensive support domain. More specifically, seven devices have functions that could enhance social communication in the sub-domains, followed by five devices designed to improve cognitive functions. In the physical support domain, four devices contain content designed to on provide physical information, three have physical monitoring functions and, two contain care management. In short, most of the devices have been developed to include content that enhances one or two functions rather than take an integrated approach to elderly care. In terms of pricing, [Case 1], [Case 2], and [Case 9] are provided on a pay-for-use basis, charging 
usage fees as well as device charges, while regarding the other devices, smartphone apps and websites are available on a complimentary basis, except for prototypes.

According to the analysis results on devices supporting each domain, the content of social interaction domain are included the most, two devices have the content that manages care support through care management. It includes care management and care schedule management among the physical support domain. And three devices contain the content of health care monitoring in the physical support domain, which was relatively small. Support for these two domains facilitates responses to various emergencies such as falls and wandering and can reduce care burdens by supporting the daily life and health management of the elderly, as well as playing a key role in elderly safety. In a report called e-Connected Family Caregiver of the US NAC (2014), a survey that collected responses from the families who were providing care work regarding the most useful devices, revealed that $40 \%$ or more of families gave an answer that the devices would be highly helpful, including health record tracking systems, medication support systems, and caregiving coordination systems. These findings suggest that related content should be strengthened because devices with such usages could significantly reduce elderly care burden.

\section{Conclusions}

It analyzed smart devices that provide elderly care support functions to prevent the issues that can arise in the care area and reduce the support burden of caregivers. The devices discussed herein are not necessarily for the elderly or intended to reduce the elderly care burden. However, this study sought to identify currently available smart devices that could assist with elderly care, and defined the domains of caring these devices target to analyze their applicability in each domain.

This study assumed that the use of systems that supports caregiving is required coping with the limitations of private elderly caregiving settings. In this respect, it constructed a theoretical framework for caregiving support technology and devices, and conducted a case study on of target devices by constructing domains based on this framework.

By classifying the devices in terms of elderly care support, the analysis showed that these devices typically provide support for one or two domains rather than integrated support through various types of content. Because various types of supports are required as the health of the elderly deteriorates, a more intentional combination of content domains is necessary to improve caregiving. A study by Kim and Choi[24] regarding technology use barriers and 
motivational factors among the elderly revealed that certain groups of seniors have no interest in any device. Despite differences in adaptability to devices and usability, depending on education level, previous experience, and exposure frequency, training in the use of smart devices is required due to the stress created by arising new devices. In another study, by Ahn and Lee[25], which surveyed the intention to use smart technology, $72.4 \%$ of long-term care workers rated smart technology as positive (i.e., answered more than average) while smart technology usage intentions were directly and indirectly affected by the perceived ease of use and perceived usefulness.

The findings of this study highlight, the need to provide training to increase the ease of use of devices among the elderly, and they also demonstrate that the devices that provide comprehensive support in as many domains as possible are effective increasing usefulness for the elderly. No devices for the elderly currently provide such integrated support in South Korea. Although this study mainly surveyed overseas cases in each domain, while some domains are under trials for introduction into South Korea. Nevertheless, the two cases of integrated support that encompassing the most diverse domains of caring support content, which would play a positive role in providing elderly care, are US cases. Thus, such development or introduction should be developed and introduced in South Korea. Of course, there should also be concerns about whether there will be any negative areas of whether integrated approach by smart devices will be effective and efficient[26][27].

Despite these significant findings, this study had several limitations. First of all, its proposal is not based on in-depth analysis, because the case study of overseas devices focused only on the rough content of in the care support domains based on available data and information in research articles that were obtained mainly. Furthermore, in the process of dividing classifying elderly care smart devices into five domains, the selection of devices was based on criteria developed via discussions with five experts in the field of senior studies, while it is still difficult to exclude an arbitrary portion of the study. Future research is needed more practical insights regarding the development and utilization of care support devices. It could be identified the advantages and limitations of the use of elderly care support devices through interviews with users of related devices, families who are the main caregivers, or other caregivers involved in long-term care work.

\section{References}


[2] A. Smith, Older Adults and Technology Use-Attitudes, Impacts, and Barriers to Adoption, USA: Pew Research Center, (2014)

[3] European Commission, ICT \& Ageing-European Study on Users, Markets and Technologies Final Report, European Commission, (2010)

[4] B. Irvine, M. B. Billow, D. M. Gates, E. L. Fitzwater, J. R. Seeley, M. Bourgeois, An Internet Training to Reduce Assaults in Long-term Care, Geriatric Nursing, (2012), Vol.33, No.1, pp.28-40.

[5] NAC(National Alliance for Caregiving), Catalyzing Technology to support Family Careginving, USA: National Alliance for Caregiving, (2014)

[6] E. N. Kang, M. H. Lee, An Exploratory Study of Social Network Type among Nursing Home Residents: Focusing on External Relationship Resources of Nursing Facilities, Health and Social Welfare Review, (2014), Vol.34, No.2, pp.133-160.

[6] S. J. Park, Y. H. Hwang, Death Awarenes and Death Preparation Experiences In Hospitalized Elderly People in a Long-Term Care Facility, International Journal of Elderly Welfare Promotion and Management, (2017), Vol.1. No.1, pp.21-28.

[7] Ministry of Health and Welfare, 2019 Survey on the Long-term Care, Korea: MOHW, (2020)

[8] E. H. Lee, S. M. Han, Complementary IT for Elderly Care Activities: From Family Caregivers' Perspectives, Journal of the Korean Gerontological Society, (2010), Vol.30, No.1, pp.159-177.

[9] S. H. Lee, J. H. Ahn, Adoption of the Use of Smart Technology by Health-care Workers in Nursing Homes: An Exploratory Study, The Journal of the Korea Contents Association, (2014), Vol.14, No.8, pp.156-171.

[10] Y. S. Kim, Current State and Development Directions for Dementia Care Technology, Health and Welfare Policy Forum, (2019), Vol.276, pp.42-57.

[11] H. H. Dodge, J. Zhu, N. C. Mattek, M. Bowman, O. Ybarra, K. Wild, A. D. Loewenstein, J. A. Kaye, Web-Enabled Conversational Interactions as a Means to Improve Cognitive Functions: Results of a 6-Week Randomized Controlled Trial, Alzheimer's \& Dementia: Translational Research \& Clinical Interventions, (2015), Vol.1, No.1, pp.1-12.

[12] D. F. Muñoz Sáez, F. J. Gutierrez, S. F. Ochoa, N. Baloian, Social Connector: A Ubiquitous System to Ease The Social Interaction among Family Community Members, Computer Systems Science and Engineering, (2015), Vol.30, No.1, pp.57-68.

[13] T. Damianakis, M. Crete-Nishihata, KL, Smith, RM, Baecker, E., Marziali, The Psychosocial Impacts of Multimedia Biographies on Persons with Cognitive Impairments, Gerontologist, (2010), Vol.50, No.1, pp.23-35.

[14] B. Dara-Abrams, Toward a Model for Collaborative Gerontechnology: Connecting Elders and Their Caregivers The Sixth International Conference on Creating, Connecting and Collaborating through Computing, (2008), January 14-16; Poitiers, France

[15] http://www.grandcare.com/, Apr 29 (2020)

[16] http://in2l.com/, Apr 29 (2020) 
[17] http://www.telikin.com/, Apr 29 (2020)

[18] https://play.google.com/store/apps/details?id=com.carezone.caredroid.careapp.medications\&hl=ko, Apr 29 (2020)

[19] http://launcher.necta.us/, Apr 29 (2020)

[20] http://www.aal-europe.eu/, Apr 29 (2020)

[21] https://www.carepredict.com/, Apr 29 (2020)

[22] F. J. M. Meiland, B. J. J. Hattink, T.Overmars-Marx, M. E. de Boer, S. Nicolai, S. Verhaeghe, C. de Coster, M. van Blanken, P. W. G. Ebben, I. N. W. Stalpers-Croeze, C. M. P. M. Hertogh, J. van der Leeuw, I. P. Karkowski, R. M. Dröes, User Evaluation of The Rosetta Assistive Technology System for People with Dementia, AAL Forum proceedings, (2012), September 24-27; Eindhoven, The Netherlands

[23] N. Savitch, R. Dutton, D. Brooks, A. Walker, My life - A Case Study of The Ethics of User Involvement in Field Trials Across Europe, AAL Forum proceedings, (2012), September 24-27; Eindhoven, The Netherlands

[24] K. Kim, W. Choi, Barriers and Motivators to Technology Use among Older Adults Implications for motivating healthy lifestyle, Korea Society for Wellness, (2014), Vol.9, No.2, pp.153-168.

[25] J. H. Ahn, S. H. Lee, Factors Associated with Usage Intention of Smart Technology in Long-Term Care Facilities: Based on the Technology Acceptance Model(TAM \& TAM2), Korean Journal of Gerontological Social Welfare, (2015), No.68, pp.357-388

[26] Y. J. Kim, S. J. Lee, Evaluation Grades of the Long-term Care Service Institutions and Quality of Service of Care Worker, International Journal of Elderly Welfare Promotion and Management, (2018), Vol.2, No.2, pp.55-60.

[27] M. R. Lee, A Study on the Effect of the Lonely Death Prevention Project on the Elderly Living Alone, International Journal of Elderly Welfare Promotion and Management, (2018), Vol.2. No.2, pp.19-24. 